\title{
Sustainable transport solutions for olympic town in Tokyo bay 2020
}

\begin{abstract}
The objective of this study is to present the result of research of Special Roundabout for replacing traffic light. The necessity, possibility and effectiveness of Special Roundabout will be analysed in detail to form the basis for design.
\end{abstract}

Keywords: special roundabout, sustainable transport, tokyo
Volume 2 Issue 4 - 2017

\author{
Pham Van Hung,' Nguyen Nam, ' Vu Thanh \\ Long, ${ }^{2}$ Doan Cong Bien' \\ 'University of Transport and Communications, Vietnam \\ ${ }^{2}$ Transport Engineering Design INC-TEDI,Vietnam
}

Correspondence: Doan Cong Bien, University of Transport and Communications, Vietnam,

Email doancongbien96@gmail.com

Received: February 22, 2017| Published: April 06, 2017

\section{Introduction}

Roundabouts should be considered at a wide range of intersection types including but not limited to, freeway terminal interchanges, state route intersections, and state route/ local route intersection. ${ }^{1,2}$ In Japan, most of the intersection used traffic light system and Japan has a notorious earthquake history. Furthermore, the using of traffic lights are energy dependent, upon the occurrence of natural disasters provide energy sources for transport may be affected directly. Hence, Japan replacing traffic light junctions with roundabouts to improve traffic flow, reduce accidents and cut energy consumption. The paper shows special roundabouts replacing signal lights at intersections. Roundabouts perform better at intersections with roughly similar traffic volumes and at intersections with heavy left turning movements. Moreover, it can improve safety by simplifying conflicts, reducing vehicle speeds and providing a clearer indication of the driver's rightof-way compared to other forms of intersection control.

Using Roundabout reduce to suffer damaged, especially the energy saving that is not only for Olympic and also creates the sustainable development of Tokyo Bay in particular and Japan in general. The study was carried out at location along Takeshita street leading to Yumenoshima stadium with the Olympic statue is the highlight attracting the tourist to the Stadium (Intersection 1). Intersection 2 changes two continuous 4-leg intersections into 5-leg intersection.

\section{Methodology}

\section{Basic geometric elements of a Roundabout}

The process of designing roundabouts, more so than other forms of intersections, requires a considerable amount of iteration among geometric layout, operation analysis, and safe evaluation. As described in Figure $1 \&$ 2, minor adjustments in geometry can result in significant changes in the safety and/or operational performance. Thus, the designer often needs to revise and refine the initial layout attempt to enhance its capacity and safety. It is rare to produce an optimal geometric design on the first attempt.

Roundabouts operate by gap acceptance, in that approaching drivers must give way to circulating traffic in the roundabout. The proven safety performance of most roundabouts is due to the low relative speeds of all vehicles and the relative simplicity of decision making required of drivers.

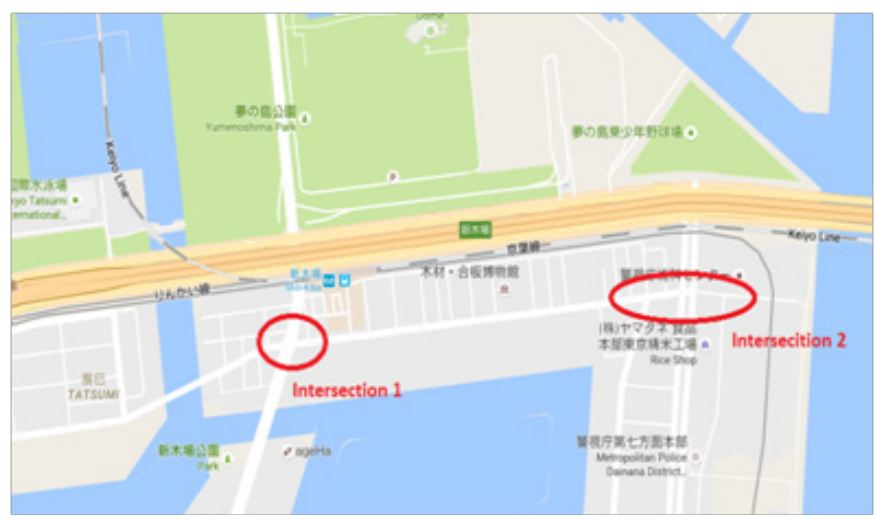

Figure I The area zoning design in Tokyo.

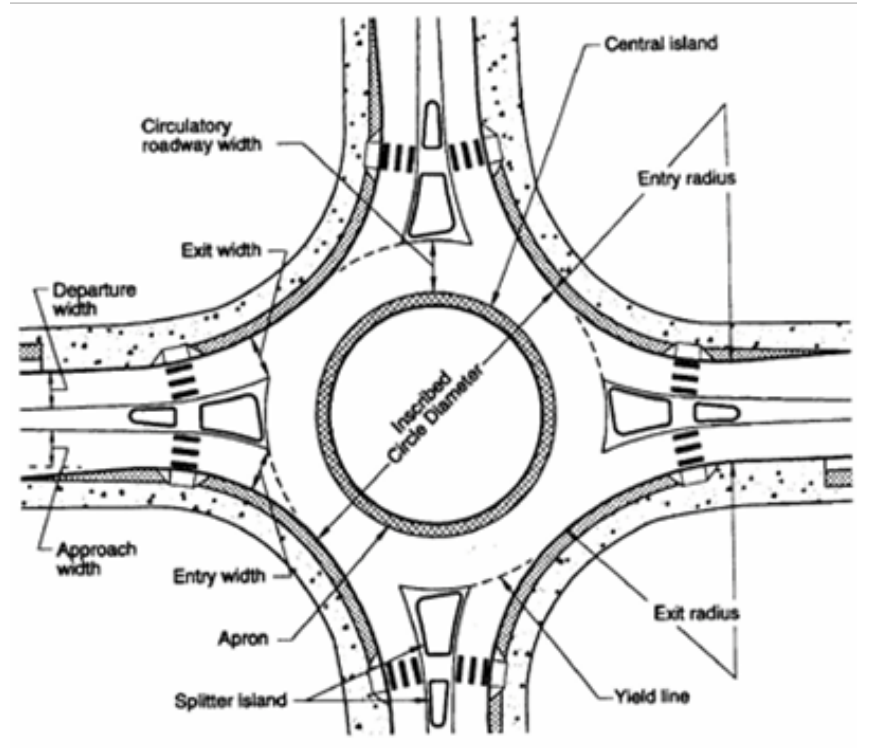

Figure 2 Basic geometric elements of a roundabout. 


\section{Special roundabout design}

\section{a. Inscribed circle diameter and central island}

The size of the roundabout is a compromise between making it small enough to provide adequate deflection while making it large enough to provide for the appropriate design vehicles. The diameter of Central Island is entirely dependent upon the inscribed circle diameter and the required circulatory roadway width. Furthermore, special design with apron and it can be used to accommodate the occasional large vehicle. According to AASHTO, ${ }^{3}$ (Table 1) and FHWA, ${ }^{4}$ (Table 2 ) and the number lanes in roundabouts. The good basis design should be avoid short lengths of reverse curve between entry and exits. Thus, it is difficult to achieve this on three-legged roundabout or on roundabouts with skewed entries.

Table I Minimum circulatory lane widths for two-lane roundabouts

\begin{tabular}{llll}
\hline Inscribed circle & $\begin{array}{l}\text { Minimum } \\
\text { circulatory }\end{array}$ & Central island & $\begin{array}{l}\text { Inscribed } \\
\text { circle }\end{array}$ \\
\hline Diameter & Land width & Diameter & Diameter \\
\hline $45 \mathrm{~m}(150 \mathrm{ft})$ & $9.8 \mathrm{~m}(32 \mathrm{ft})$ & $25.4 \mathrm{~m}(86 \mathrm{ft})$ & $45 \mathrm{~m}(150 \mathrm{ft})$ \\
$50 \mathrm{~m}(165 \mathrm{ft})$ & $9.3 \mathrm{~m}(31 \mathrm{ft})$ & $31.4 \mathrm{~m}(103 \mathrm{ft})$ & $50 \mathrm{~m}(165 \mathrm{ft})$ \\
$55 \mathrm{~m}(180 \mathrm{ft})$ & $9.1 \mathrm{~m}(30 \mathrm{ft})$ & $36.8 \mathrm{~m}(120 \mathrm{ft})$ & $55 \mathrm{~m}(180 \mathrm{ft})$ \\
$60 \mathrm{~m}(200 \mathrm{ft})$ & $9.1 \mathrm{~m}(30 \mathrm{ft})$ & $41.8 \mathrm{~m}(140 \mathrm{ft})$ & $60 \mathrm{~m}(200 \mathrm{ft})$ \\
$65 \mathrm{~m}(215 \mathrm{ft})$ & $8.7 \mathrm{~m}(29 \mathrm{ft})$ & $47.8 \mathrm{~m}(157 \mathrm{ft})$ & $65 \mathrm{~m}(215 \mathrm{ft})$ \\
$70 \mathrm{~m}(230 \mathrm{ft})$ & $8.7 \mathrm{~m}(29 \mathrm{ft})$ & $52.6 \mathrm{~m}(172 \mathrm{ft})$ & $70 \mathrm{~m}(230 \mathrm{ft})$ \\
\hline
\end{tabular}

Table 2 Recommended maximum entry design speeds

\begin{tabular}{ll}
\hline Site category & $\begin{array}{l}\text { Recommended maximum } \\
\text { entry design speed }\end{array}$ \\
\hline Mini-Roundabout & $25 \mathrm{~km} / \mathrm{h}$ \\
Urban Compact & $25 \mathrm{~km} / \mathrm{h}$ \\
Urban Single Lane & $35 \mathrm{~km} / \mathrm{h}$ \\
Urban Double Lane & $40 \mathrm{~km} / \mathrm{h}$ \\
Rural Single Lane & $40 \mathrm{~km} / \mathrm{h}$ \\
Rural Double Lane & $50 \mathrm{~km} / \mathrm{h}$ \\
\hline
\end{tabular}

\section{b. Circulatory roadway width}

Circulatory roadway should not arrange over from 3 to 4 lanes. It should be ensure enough the width for trucks, containers, buses going through in roundabouts. And, it is not require the long mixing lane or no mixing lane. For the intersection with two lanes, the minimum circulatory should be following ASSHTO (Table 1).

\section{c. Entry width and exit width}

Entry width can vary depending on the design vehicle and approach roadway width. The entry width should be less than or equal to the circulating width. In the end, the entries should be designed to accommodate the design vehicle when ensuring adequate deflection.

The exit from a roundabout should be easy to negotiate as possible. Whereas entries are designed to slow vehicles, exiting vehicles should be able to accelerate out of the circulating roadway. Therefore, the exit radii should generally be greater than entry radii.

\section{d. Pedestrian design}

In the planning and design of roundabouts, special thought should be given to the movement of pedestrians. There are two reasons: firstly, the speed of all vehicles is slower at a roundabout intersection. Secondly, pedestrians use the splitter island as a refuge area Figure 3. Hence, the pedestrian only crosses one stream of traffic at a time. Moreover, consideration should be given to providing priority crossings for pedestrians where pedestrian volumes are very. Where there is a high percentage of young, elderly of infirm citizens wanting to cross the road.

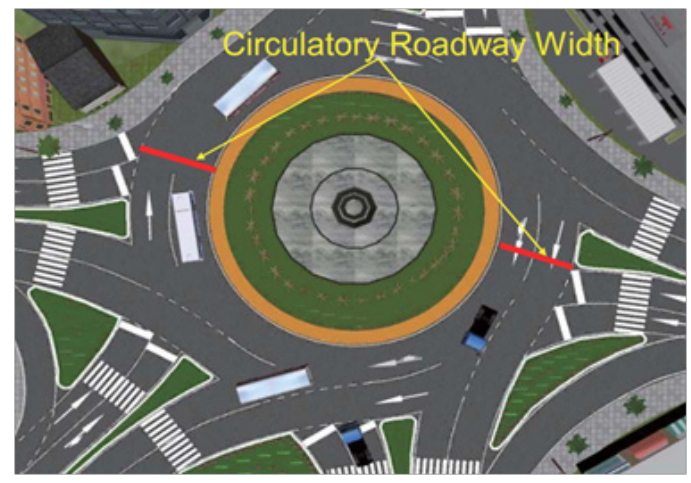

Figure 3 Circulatory roadway width for 2 lanes in the roundabout.

Typically at roundabouts, the location of the crosswalk is $6 \mathrm{~m}$ from the edge of the circulatory roadway or yield line (following the SHA Pedestrian and Bicycle Design Guidelines). Splitter islands should be provided on all roundabouts. They provide shelter for pedestrians, guide traffic into the roundabout, and deter left turns from dangerous short-cuts through the roundabout Figure $4 \& 5$.

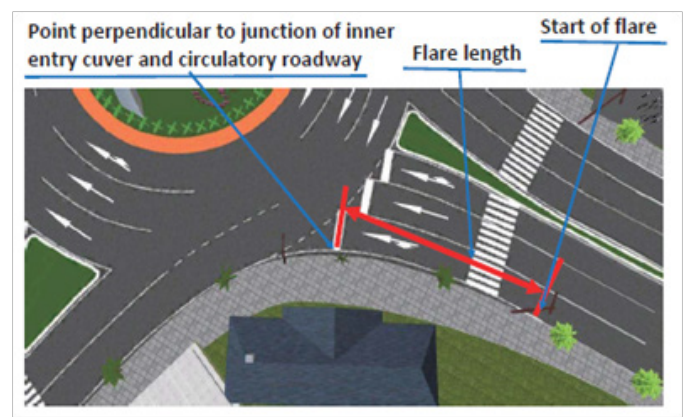

Figure 4 Typical roundabout entrance/exit.

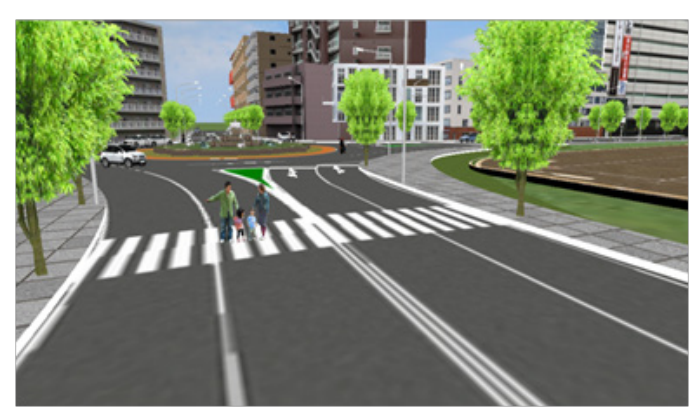

Figure 5 Example of pedestrian crossings.

The geometric of splitter islands is designed with total length $15 \mathrm{~m}$, and pavement markings should be constructed within the splitter island envelope about 7.5. In that case, use Figure 6 shown below of the splitter islands. 


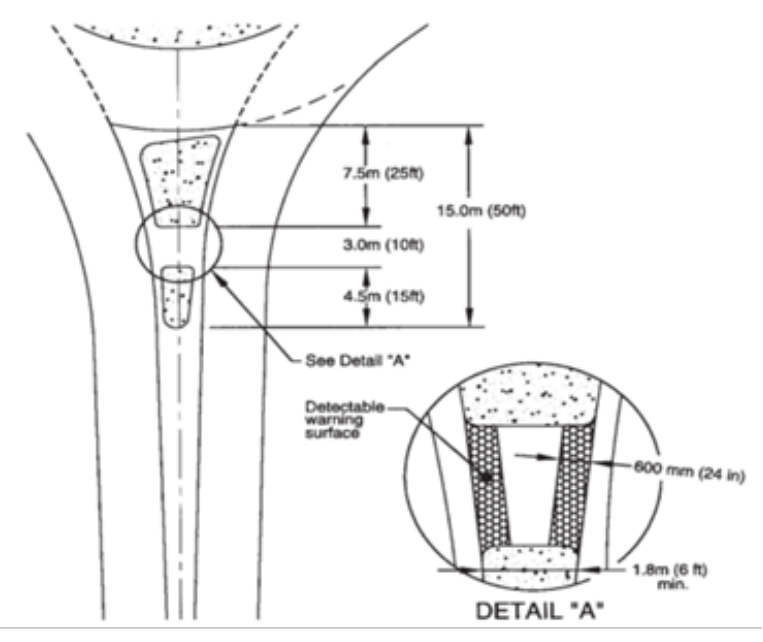

Figure 6 Splitter island design for the pedestrian.

\section{e. Bicycle design}

I. Since maximum entry speeds for roundabouts are between 25 and $30 \mathrm{~km} / \mathrm{h}$, bicyclists should be able to navigate the roadway of a roundabout safety.

II. To provide a satisfactory level of safety for cyclists at roundabouts, particular attention will need to be taken in the layout design to:

III. Ensure that adequate deflection and speed control is achieved on entry and through the roundabout.

IV. Avoid large than necessary roundabout diameter, thus reducing travel speed through the roundabout.

V. Avoid excessive entry widths and alignments which can also go up vehicle entry speeds.

VI. Ensure that sight lines are not obstructed by landscaping, traffic signs or poles which may even momentarily obscure a cyclist.

VII. Provide adequate lighting.

Normally, if high volumes of bicycle traffic exist, a special bicycle facility could be constructed as shown in Figure 7.

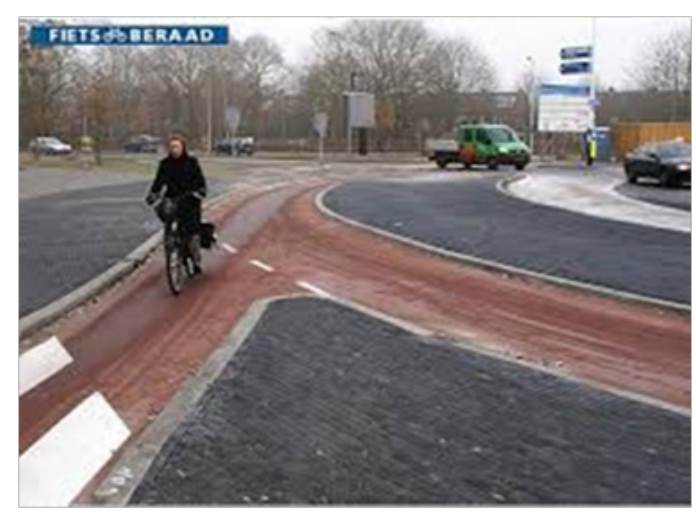

Figure 7 Example of a special bicycle facility.

\section{f. Lighting system design}

Permanent lighting should be used to light the work area. As the number of roundabouts in the world continues to grow, local road authorities are interested to roundabout lighting to enhance pedestrian safety while reducing ongoing energy costs Figure 8-12.

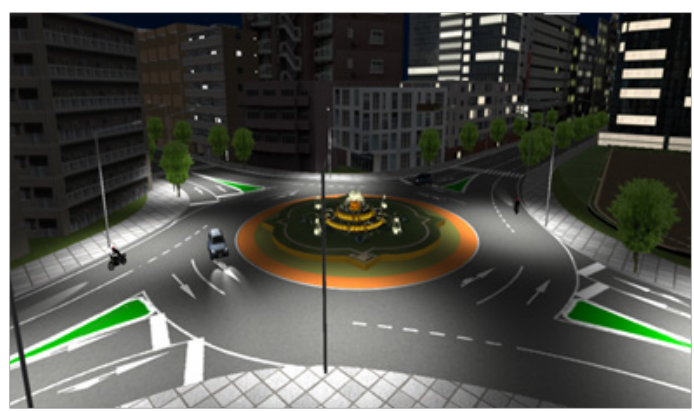

Figure 8 Roundabout lighting design in the night.

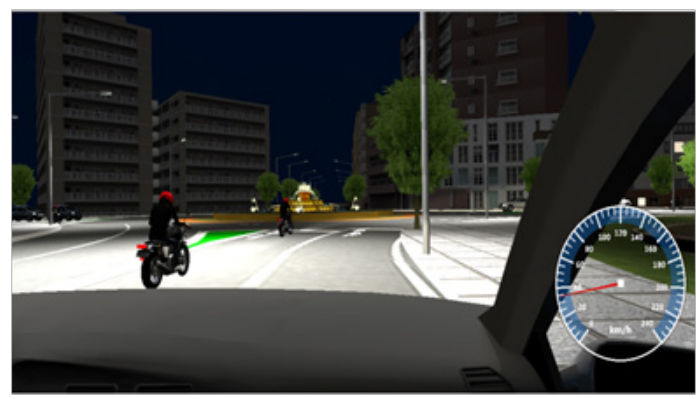

Figure 9 Example visibility from the car at roundabout.
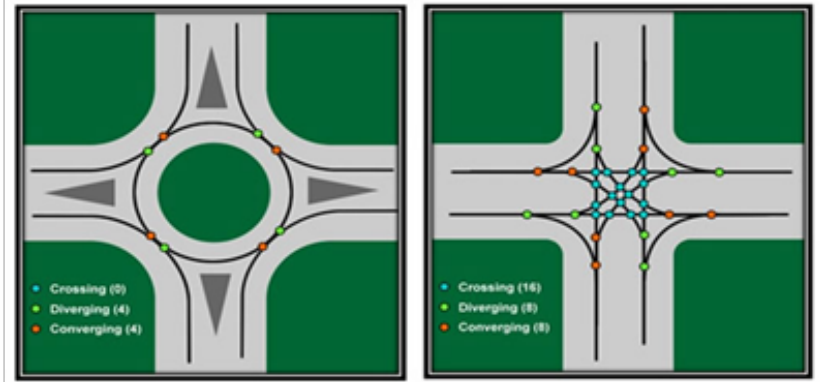

Figure $10 \mathrm{~A}$ comparison of possible collision points on a roundabout versus a traditional intersection.
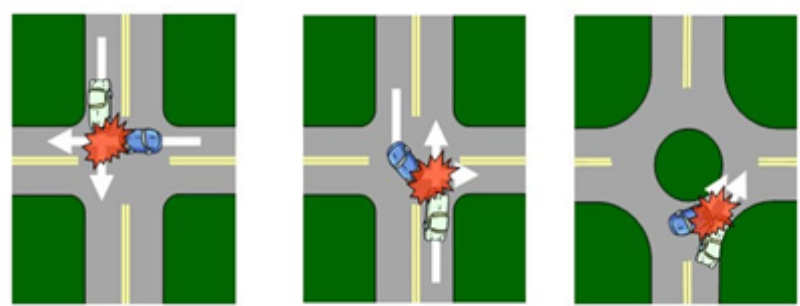

Figure I I Modelling the accident happen at the intersection and roundabout.

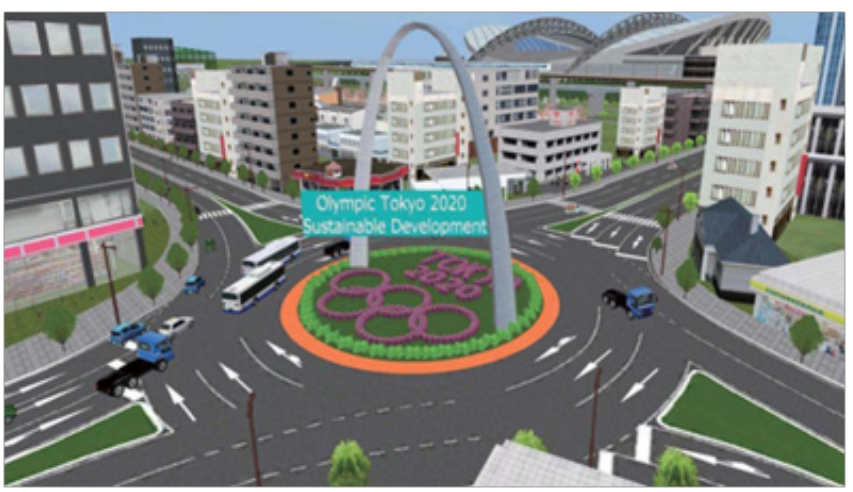

Figure 12 Modeling Roundabout in Shinkiba/Tatsumi. 
Landscape the central island is designed to increase its visibility from the approach roadways. In addition to landscaping, advanced warning signs, pavement markings, and rumble strips may also be necessary to enhance visibility and driver awareness of the roundabout.

\section{g. Calculate absorption capacity in the roundabout}

The absorption capacity of each entry lane is computed from the entry lane gap acceptance velocity of vehicle. Following the NCHRP Report 672, the appropriate equation from $0-1$ to $0-2^{5}$ is:

For the one lane in the roundabout

$$
\mathrm{C}=1130 . \exp (-0,001 . v \mathrm{c}) 01
$$

Where:

$C$ is the absorption capacity of an entry lane in $(\mathrm{Veh} / \mathrm{h})$

$v_{c}$ is the flow of vehicles in the circulating streams in Veh/h

For the two lane in the roundabout

$$
\mathrm{C}=1130 . \exp (-0,007 . \mathrm{vc}) 02
$$

\section{Traffic safety at roundabouts}

Roundabouts can provide lasting benefits and value in many ways. They are often safer, more efficient, less costly and aesthetically appealing than conventional intersection designs. Most significantly, roundabouts reduce the types of crashes where people are seriously hurt or killed by $78-82 \%$ when compared to conventional stopcontrolled and signalized intersections, per the AASHTO Highway Safety Manual. By reducing the number and severity of conflict points, and because of the lower speeds of vehicles moving through the intersection, roundabouts are a significantly safer type of intersection. Not only are conflict points halved with the roundabout Figure 13, the type of conflicts that remain are the same-direction variety, which result in substantially less severity, and as a result, less likelihood of injury. The reduction of both the total number of conflict points and their severity is also true for pedestrian.

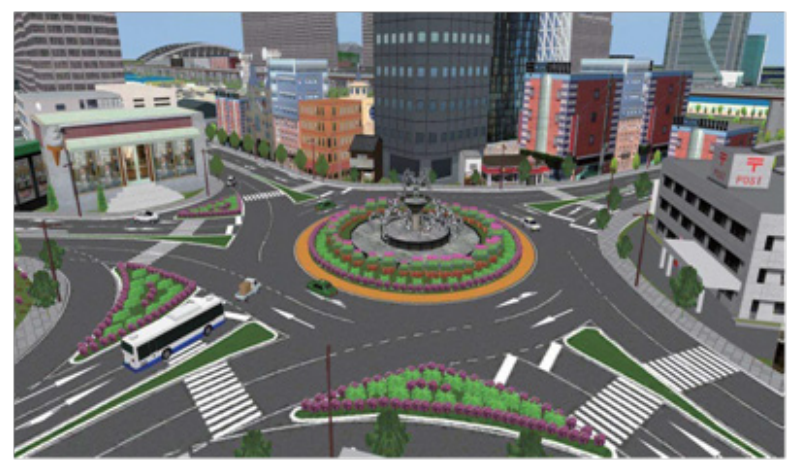

Figure 13 Modeling Roundabout in an intersection 2.

Roundabouts are safer than traffic circles and junctionsexperiencing 39\% fewer vehicle collisions, $76 \%$ fewer injuries and $90 \%$ fewer serious injuries and fatalities (according to a study of a sampling of roundabouts in the United States, when compared with the junctions they replaced).

\section{Result and discussion}

Roundabouts can offer considerable scope for environmental enhancement and are often favored over other forms of intersection treatment in environmentally sensitive areas. In addition, compared to traffic signals, roundabouts may operate with reduced queue lengths and shorter average delays. These results in:

a. Make a green- ecology city.

b. Minimize the noise and pollution.

c. Saving the energy.

d. No much costs for build, manage and exploit.

Moreover, the use of roundabout eliminates potential traffic safety and disruption problems associated with the malfunction of traffic signals and ensure transporting in case occurring earthquake. The cost of roundabout installation varies a great deal between sites depending on factors such as the area of pavement construction and other road works, the cost of land acquisition and the relocation of services. However, when completing a benefit/cost for a roundabout, the life cycle costs for the anticipated duration of the improvement should be considered.

Moreover, the modeling has been tested on a simulation on BIM VR technology, and more professors from Harvard University, Keio and RMIT appreciated. ${ }^{6}$

\section{Conclusion}

In earthquake-prone Japan, the lack of a signal has the additional benefit that traffic can flow normally even during a blackout, making evacuation easier. Japan replacing traffic signal junctions with roundabouts to improve traffic flow, reduce accidents and cut energy consumption. The high passing capacity meets the increasing transport demand not only for the Olympic but also for the sustainable development in the future in Tokyo. In addition, ensure transporting in case occurring earthquake. Thus, it is tackle for sustainable intersection in a metropolis.

In view of the shortage of published information on foundations it is recommended that further studies should be undertaken into this area.

\section{Acknowledgements}

None.

\section{Conflict of interest}

The author declares no conflict of interest.

\section{References}

1. Roundabout design guilines. Supplement to the NCHRP Report 672 Roundabouts: An Informational Guide. 2nd ed. Maryland State Highway Administration; 2010. 32 p.

2. Department of Transport (United Kingdom). Geometric Design of Roundabouts TD 16/93. 1993.

3. American Association of State Highway and Transportation Officials (AASHTO). A Policy on Geometric Design of Highways and Streets. Washington, USA.

4. Federal Highway Administration (FHWA). Washington, USA; 2009.

5. NCHRP Report 672. Roundabout: An Informational Guide.

6. Tokyo-Sustainable Development, INED-UT team. University of Transport and Communications. 